\title{
Coronary artery perforation treated with multiple bare metal stent implantation
}

\author{
Murat Baskurt¹, Kudret Keskin¹, Osman Fazlıoğulları², Burak Ayça³, Muhsin Kalyoncu \\ ${ }^{1}$ Cardiology Department, Medicana Hospitals Bahçelievler, Bahçelievler, Istanbul, Turkey \\ ${ }^{2}$ Cardiovascular Surgery Department, Medicana Hospitals Bahçelievler, Bahçelievler, Istanbul, Turkey \\ ${ }^{3}$ Cardiology Department, Bağcılar Education and Research Hospital, Bağcılar, Istanbul, Turkey \\ ${ }^{4}$ Safa Hospital, Bağcılar, Istanbul, Turkey
}

Postep Kardiol Inter 2013; 9, 4 (34): 397-400

DOI: $10.5114 /$ pwki.2013.38874

\begin{abstract}
A bstract
Although coronary artery perforations are quite rare, when they occur, the consequences are devastating. Treatment options differ according to the type, location and severity of the perforation. As a general rule severe perforations are treated with covered stents. However, when implanting a covered stent is not an option as in our case due to various reasons, multiple bare metal stent implantation may be a good option. Besides that, management of the antiplatelet and the anticoagulant therapy remains controversial. We believe that therapy should be individualized.
\end{abstract}

Key words: coronary perforation, covered stent, cardiac tamponade.

\section{Introduction}

Coronary artery perforation is one of the most feared complications in invasive cardiology. Fortunately it is a rare complication with an incidence of $0.1-0.8 \%$ [1].

Severe perforations are generally treated with a covered stent. Although covered stents remain the final percutaneous choice and may help avoid surgery, they have an inherently greater risk of thrombosis and restenosis [2]. In a situation where a covered stent is not available or cannot be delivered, implantation of one or two additional bare metal stents (BMS) may also be curative in coronary perforations. In our case due to lack of a covered stent at that moment, we implanted two more bare metal stents inside each other, resulting in complete sealing of the perforation. However, there is a lack of data in the management of the antiaggregant and anticoagulant therapy in the short term after sealing the perforation.

\section{Case report}

A 55-year-old man was taken to the catheterization laboratory with a history of stable angina pectoris in the last three months. His physical examination, surface ECG, echocardiogram and laboratory tests were within normal limits. At the angiogram, which was performed via the right radial artery, there were two significant lesions in the RCA and LAD. After the informed consent, we decided to open the LAD lesion first. LAD artery was wired with a 0.014 inch Floopy (Asahi Japan) guidewire. The lesion was predilated with a $2.0 \mathrm{~mm} \times 15 \mathrm{~mm}$ Sprinter balloon (Medtronic USA) at $12 \mathrm{~atm}$. Then a $3.0 \mathrm{~mm} \times 32 \mathrm{~mm}$ Liberte BMS (Boston Scientific, USA) was implanted at $16 \mathrm{~atm}$. Due to plaque shift and residual stenosis at the distal part of the first stent, a second $2.75 \mathrm{~mm} \times 18 \mathrm{~mm}$ Nobori (Terumo Japan) drug-eluting stent was implanted at 18 atm overlapping the proximal one (Figure 1). After the control angiography, the mid part of the stented area seemed not fully opened and it was decided to apply postdilation. A $3.0 \mathrm{~mm} \times 15 \mathrm{~mm}$ Sprinter balloon was inflated at 18 and then $20 \mathrm{~atm}$. Since the result was not satisfactory, a $3.5 \mathrm{~mm} \times 16 \mathrm{~mm}$ Sprinter balloon was once more inflated at $20 \mathrm{~atm}$ (Figure 2). During this last inflation, the waist of the balloon suddenly disappeared, giving the impression of full expansion. Further injection revealed Ellis type 3 perforation of the vessel from just beneath the overlapped region (Figure 3).

The postdilatation balloon inflated immediately at the same site with a lower atm approximately for $10 \mathrm{~min}$. After $10 \mathrm{~min}$ there was no difference in the leakage.

\section{Corresponding author:}

Kudret Keskin, Cardiology Department, Medicana Hospitals Bahçelievler, Bahçelievler, Istanbul, Turkey, tel.: +90 2124491449 ,

fax: +90 212 558009, e-mail: keskinkudret@yahoo.com

Received: 30.05.2013, accepted: 8.08.2013. 


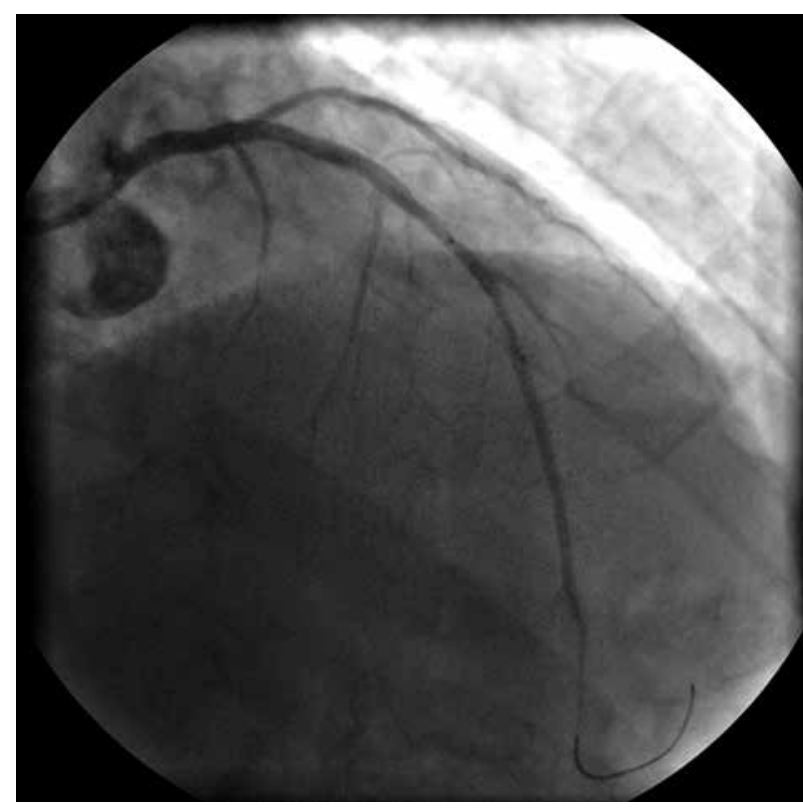

Fig. 1. A significant stenosis is seen between the markers of the bare metal stent in the mid segment of the LAD (left anterior descending) artery

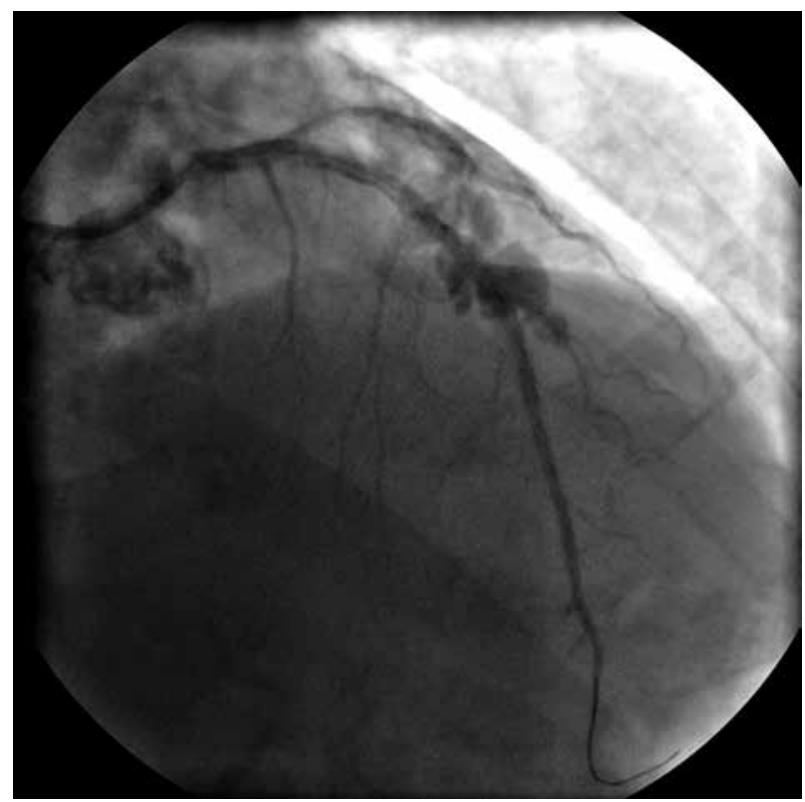

Fig. 3. Ellis type 3 coronary perforation is seen

Balloon inflation was performed for $10 \mathrm{~min}$ more and again nothing changed. Since it was an ad-hoc procedure, the patient was aspirin and clopidogrel naive and only $7500 \mathrm{IU}$ heparin and $25 \mu \mathrm{g} / \mathrm{kg}$ bolus tirofiban were administered during the procedure. Heparin was neutralized with protamine.

Because of continuous leakage, we decided to implant a BMS at the perforation site since a covered stent was

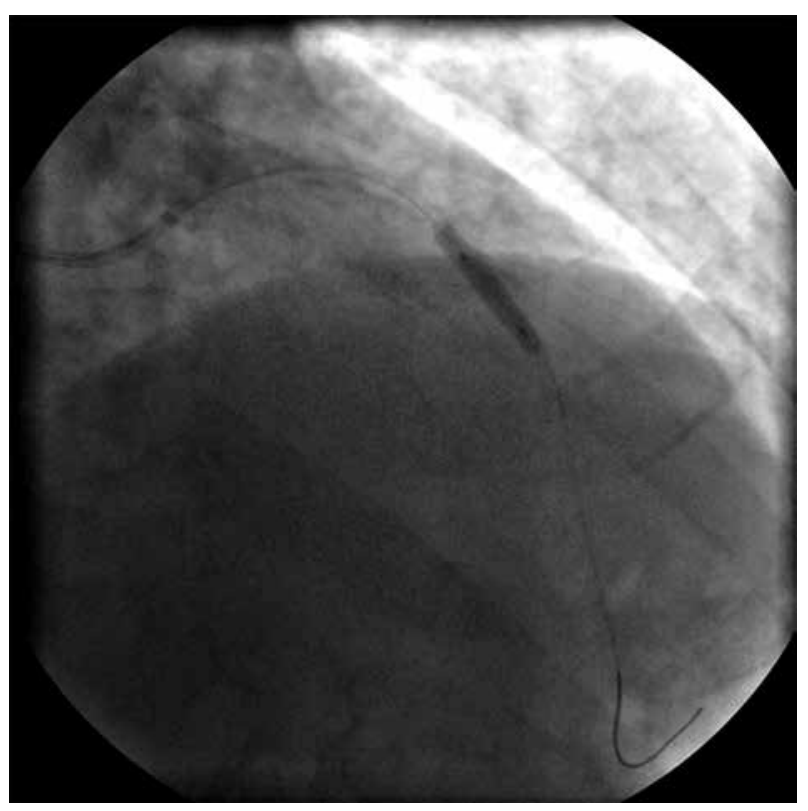

Fig. 2. The fully expanded $3.5 \mathrm{~mm} \times 20 \mathrm{~mm}$ Sprinter balloon at $20 \mathrm{~atm}$ shows a small amount of bulging in the mid portion

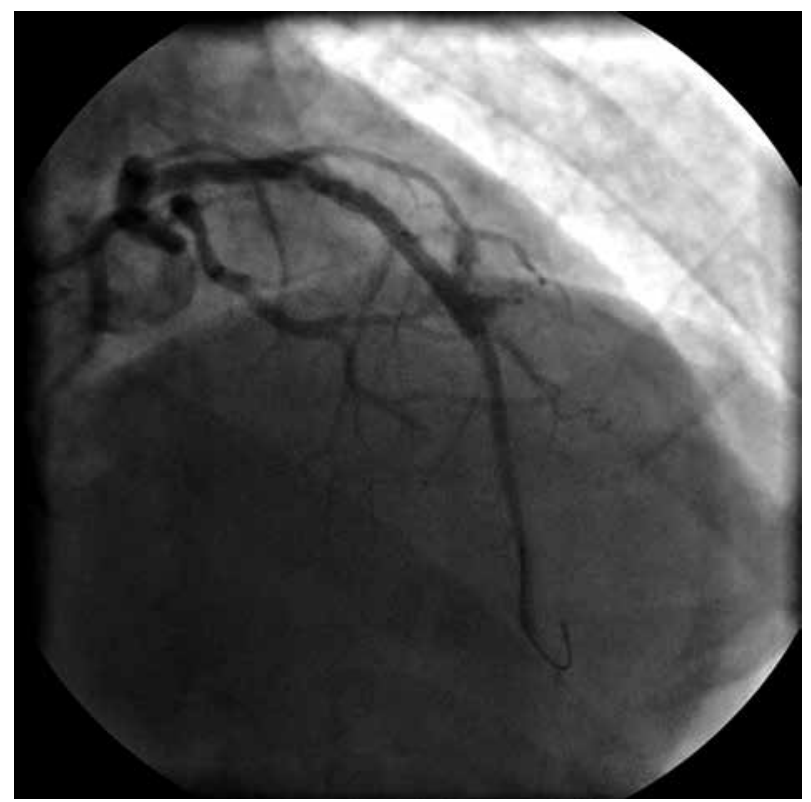

Fig. 4. After first bare metal stent implantation following prolonged balloon inflation diminished but ongoing leakage is seen

not available in the laboratory. A $3.0 \mathrm{~mm} \times 16 \mathrm{~mm}$ Liberte BMS was implanted at 16 atm which diminished the leakage (Figure 4). In order to seal the perforation completely, a second $3.0 \mathrm{~mm} \times 16 \mathrm{~mm}$ Liberte BMS was implanted at $16 \mathrm{~atm}$ at the same site. Control angiography showed no extravasation (Figure 5). After that the patient exhibited shortness of breath and his blood pressure dropped from $130 / 70 \mathrm{~mm} \mathrm{Hg}$ to $70 / 40 \mathrm{~mm} \mathrm{Hg}$ along with tachycardia. 


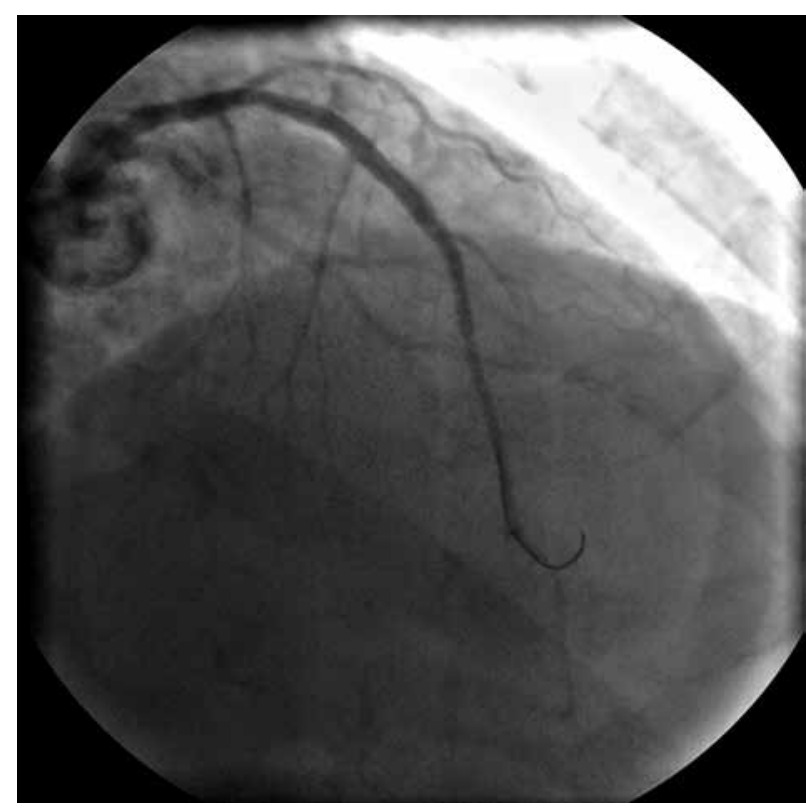

Fig. 5. After second bare metal stent implantation, there is no more contrast extravasation into the pericardial space. This is evaluated as complete sealing of the coronary perforation

Emergent echocardiography revealed $0.7 \mathrm{~cm}$ pericardial effusion with right heart compromise. This was considered as cardiac tamponade. Immediate puncture and drainage of $50 \mathrm{ml}$ pericardial hematoma with a $6 \mathrm{Fr}$ sheath corrected blood pressure, tachycardia and dyspnea. One last shot showed no signs of perforation and the patient transferred to the coronary care unit for further therapy leaving the sheath in place in case of tamponade recurrence.

On that night, because of the fear of cardiac tamponade recurrence, aspirin and clopidogrel were not administered. Instead, we decided to proceed with tirofiban infusion at a dose of $0.05 \mu \mathrm{g} / \mathrm{kg} / \mathrm{min}$ because of the thrombogenicity of three layers of stent struts and the risk of stent thrombosis. Serial echocardiograms were performed every $3 \mathrm{~h}$ for detecting any new fluid accumulation. The next morning, the sheath was removed and both clopidogrel and aspirin were started while tirofiban was stopped.

The patient had no further problems for the next 3 days and was discharged home without any complications. Ten days later the RCA was stented from a left radial approach and the LAD was found to be intact (Figure 6).

\section{Discussion}

Coronary artery perforation is a rare but potentially fatal complication of coronary interventions. Since more complex lesions are being treated by percutaneous methods, one is more prone to encounter such situations. Coronary perforations differ in severity from just dye stain-

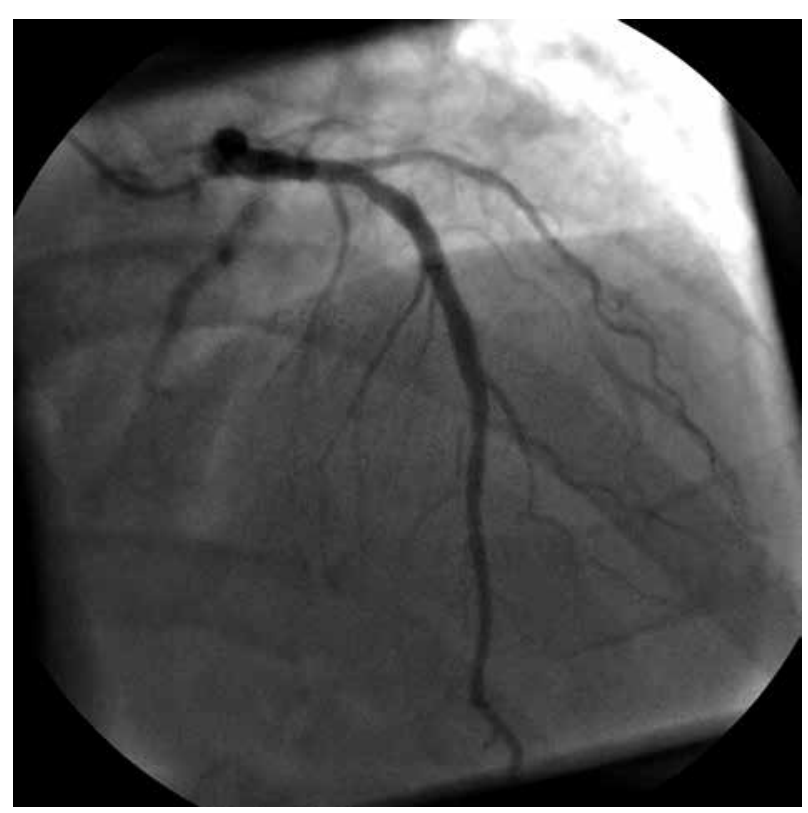

Fig. 6. LAD is seen as normal 10 days after the sealed coronary perforation

ing to the free extravasation leading to tamponade as was the situation in our case. Apart from wire perforations which are generally treated either conservatively or by other methods, balloon or stent perforations are generally treated by covered stents. Covered stents inherently have some limitations and complications both acute and chronic. Because of their bulky and stiff nature, it is hard to place them in distal and tortuous lesions. They have a higher thrombosis and restenosis rate and they are not always available. In such circumstances, multiple BMS preferably with narrow cells can be implanted into each other with nominal pressures in order to seal the perforation. There are some case reports which describe successful application of this technique [3].

Another important point is the management of anticoagulation therapy after sealing the perforation. Because of the lack of randomized trials, most recommendations are only expert opinions. If heparin is being used, it can simply be neutralized by protamine. If bivalirudin is selected, just stopping the infusion is enough [4]. There is profound controversy regarding the reversal of anticoagulant therapy. It is believed that prolonged balloon inflation may cause clotting proximal to the balloon and complicate the situation. Moreover, following implantation of a covered stent, the risk of covered stent thrombosis is not negligible $-8.6 \%$ [5]. Considering these drawbacks, there are some centers where heparin is not antagonized if covered stents are chosen [6].

For the antiplatelet therapy, since there are some case reports of fatal covered stent thrombosis, we administered tirofiban for nearly $24 \mathrm{~h}$ in order to prevent thrombosis 
of the three layer stents [7]. There are also some case reports where dual antiplatelet therapy was not interrupted as the perforation was closed [8]. Since our case was an ad-hoc procedure and the patient was aspirin and clopidogrel naive, we decided to continue with just gp2b3a inhibitor therapy. Currently, the role of novel antiplatelet agents such as prasugrel or ticagrelor is unknown in this setting.

If pericardial drainage is attempted, getting even as little as $30 \mathrm{cc}$ of blood alleviates the symptoms and corrects the hemodynamic status. Leaving the sheath in place for several hours may be a good choice in order to be ready for further leakage.

There are three take home messages in this case. The first is that the implantation of one or more additional BMS may seal the perforation and may be life saving in the absence of covered stents or failure of implantation. The second is that continuation of antiaggregant therapy after sealing may be safer than no antiaggregant therapy. The third is that keeping the sheath or pigtail catheter in place for several hours may be a standard procedure after urgent pericardiocentesis.

\section{References}

1. Ellis SG, Ajluni S, Arnold AZ, et al. Increased coronary perforation in the new device era. Incidence, classification, management and outcome. Circulation 1994; 90: 2725-2730.

2. Ly H, Awaida JP, Lesperance J, et al. Angiographic and clinical outcomes of polytetrafluoroethylene-covered stent use in significant coronary perforations. Am J Cardiol 2005; 95: 244-246.

3. Dhakam S, Rahman N. A simpler approach to seal severe coronary perforation with bare metal stent. BMJ Case Report 2010; pii: bcr0620091954.

4. Kini AS, Rafael OC, Sarkar K, et al. Changing outcomes and treatment strategies for wire induced coronary perforations in the era of bivalirudin use. Catheter Cardiovasc Interv 2009; 74: 700-707.

5. Al-Lamee R, lelasi A, Latib A, et al. Incidence, predictors, management, immediate and long-term outcomes following grade III coronary perforation. J Am Coll Cardiol Intv 2011; 4: 87-95.

6. Hendry C, Fraser D, Eichhofer J, et al. Coronary perforation in the drug-eluting stent era: incidence, risk factors, management and outcome: the UK experience. Eurolntervention 2012; 8: 79-86.

7. Fang HY, Wu CJ. Left main perforation and acute stent thrombosis - a cath lab nightmare. Catheter Cardiovasc Interv 2011; 78: 237-243.

8. Karabulut A, Topcu K. Coronary perforation due to sirolimus-eluting stent's strut rupture with post-dilatation. Kardiol Pol 2011; 69: 183-186. 